\title{
Fantasy orientation and creativity in childhood: A closer look
}

\author{
Louise Bunce, Oxford Brookes University
}

Jacqueline D. Woolley, University of Texas at Austin

Abstract:

Fantasy orientation (FO) in childhood has previously been investigated in binary terms, with play being categorised as fantastical or not. This study examined the relation between FO and creativity by considering FO on a linear-type scale, with $0=$ reality-oriented (e.g., playing basketball), 1 = possible fantasy (e.g., having a pretend tea party), 2 = improbable fantasy (e.g., pretending an alligator is hiding under the bed), and $3=$ impossible fantasy (e.g., pretending to be a unicorn). Seventy-two 4- to 7-year-old children completed verbal, physical, and artistic creativity tests, and an FO interview. FO was only positively related to physical creativity when measured in binary terms. However, it positively related to both verbal and physical creativity when measured using the four-point scale, although, FO remained unrelated to artistic creativity. Future work could use this more nuanced coding of children's FO to explore further the potential relations between FO and creativity.

Keywords: fantasy orientation; creativity; pretense; cognition; imagination; divergent thinking 
Fantasy orientation and creativity in childhood: A closer look

The cognitive benefits of a common form of childhood play, fantasy play, are yet to be fully understood. During this form of play, children may engage in fantastical thinking, which can be described as "ways of reasoning about the physical world that violate known physical principles" (Woolley, 1997, p. 993). This might involve pretending to be a wizard, pretending to live in a fairy castle, or pretending to be invisible. Some children are more fantasy-oriented in their play, and others are more reality-oriented, and this seems to be a stable individual difference throughout childhood (Woolley, 1997). Furthermore, the extent to which children engage in fantasy play may be predictive of two foundational cognitive abilities-Executive Function (Pierucci, et al. 2014; Thibodeau-Nielsen, et al. 2020) and Theory of Mind (Taylor \& Carlson, 1997; Dore \& Lillard, 2015).

Before discussing research on fantastical thinking and cognitive development, it is important to note that the term fantasy play is often used interchangeably in the literature with pretend play or pretense. Pretend play has been described as non-literal engagement with alternate identities or events, and playful behaviours that require some type of representation or acting-as-if (Weisberg, 2015). However, fantasy or pretend play can involve activities that vary across the wide spectrum of ontological commitment, from real to non-real or fantastical. At the real end of the spectrum are activities such as pretending to be ordinary entities (e.g., a teacher) and pretending to take part in real events (e.g., a tea party). At the non-real end are activities such as pretending to be fantastical entities (e.g., a fairy) and pretending to take part in fantastical events (e.g., casting a magic spell). In the current study, we examined the potential importance of differentiating children's fantasy play according to the extent to which it is truly fantastical (i.e., violates known physical 
principles) by developing a four-point fantasy orientation (FO) scale, which will be described shortly. We subsequently used this to explore potential relations between FO and creativity in childhood.

Creativity has been defined as the ability to produce ideas that are novel or original (Wallach \& Kogan, 1965). Give that fantasy play also involves an element of novelty and imagination, it is not surprising that several studies have attempted to understand potential relations between the two. One extensive review of this evidence proposed that engaging in pretend activities ('pretend' being used here in the broad sense and not distinguishing between representational and fantastical pretense) may be a 'crucial engine' of child development in some domains including language and reasoning (Lillard et al. 2013). However, the review concluded that the quality of evidence concerning relations between pretense and creative thinking was 'not convincing' (p. 8) owing to methodological flaws, such as non-blind experimenters, and narrow ways of operationalizing creativity. However, the opposite conclusion was drawn in another review that disregarded studies with low statistical power (Silverman, 2016). Silverman concluded that it is 'likely true' that pretend play (again, in the broad sense of the term, not distinguishing between representational and fantastical pretense) supports the development of creativity (p. 140).

Taking Silverman's (2016) conclusion forward, this raises the question of why fantasy and creativity might be related. Several authors have tried to answer this question. Silverman (2016) argued that processes involved in pretend play, such as identification of one object with another and projecting symbolic actions onto objects, have a lot in common with creativity processes, including generating alternatives to reality and generating new possibilities. Lillard et al. (2013) noted Dansky and Silverman's (1973) speculation that engaging in fantasy play (used to refer broadly to representational and fantastical play) may 
predispose children to a playful attitude, which may be conducive to producing novel or unusual ideas. Singer and Singer (1990) claimed that children also practise divergent thinking, a form of creativity, in their pretend play by endowing objects with multiple pretend identities over time or by developing alternate story endings. These processes, including generating alternate story endings and imaginatively manipulating event scripts (Carlson \& Zelazo, 2008), may serve to provide a form of separation between a child's thoughts and their immediate behavioural environment, which may support the generation of novel ideas (Sigel, 1970, cited in Carlson et al. 2014). Similarly, Harris (2000) and Lillard (2001) suggest that engaging in pretend play occurs at a level of representation that is separate from reality, and this may support creative thinking. Finally, engaging in pretend play (both representational and fantastical) also involves counterfactual thinking (Walker \& Gopnik, 2013), that is, generating ideas that are counter to reality, such as pretending that there is tea in an empty teapot (Harris, 2000), or that a cup contains magic potion. This type of thinking also is required to generate original, creative ideas (Magid, Sheskin, \& Schulz, 2015). Taking these arguments one step further, it could be reasoned that the more fantastical the play, the stronger the relation between play and creativity, because both high fantasy and creativity involve thinking about a broad range of possibilities that are a great distance from the real world (Runco \& Pina, 2013).

To assess the extent to which children's play is fantastical, researchers have interviewed children about their play preferences, for example, their favourite book or TV show, whether they like to take on pretend identities, and whether they have an imaginary companion (Taylor \& Carlson, 1997; Sharon \& Woolley, 2004). Taylor and Carlson (1997) used a binary measure of FO, with responses coded as reality oriented (playing tag or preferring to play with a toy puzzle) or fantasy oriented (playing 'house' or preferring to play 
with a ninja turtle) (see also Pierucci et al. 2014 and Richert \& Smith, 2011). In this scheme, any forms of pretending or play that indicated some level of representation were categorised together, that is, the level of fantasy in the fantasy-oriented category was not taken into account. In contrast, other researchers have attempted to differentiate level of fantasy to some extent, following Singer's (1973) guidelines. For example, Sharon and Woolley (2004) differentiated fantasy-oriented responses (e.g., monster game) from imaginative or representational responses without a clear fantastical element (e.g., playing fireman) and reality-oriented responses (e.g., checkers) (see also Boerger, Tullos \& Woolley, 2009; Woolley, Boerger \& Markman, 2004; Dore \& Lillard, 2015). Similarly, Thibodeau et al. (2016) differentiated between fantastical responses (e.g., fairies or superheroes), responses involving anthropomorphised or animated entities or games (e.g., stuffed animals or toy cars), and realistic responses (e.g., checkers or bingo). Researchers in these studies have typically summed the children's scores on these measures to provide an overall FO score.

These methods of coding and analysis are limited, however, for two reasons. First, the three-point scale does not take into account all levels of fantasy. Second, providing an overall FO score does not allow examination of whether there are any categorical differences between, for example, children who engage in imaginative but non-fantastical play (e.g., playing doctors) and children who are truly fantasy oriented (e.g., playing witches). These two limitations were addressed in the current study.

This study extended the method of coding children's interview responses to produce a more nuanced FO score. Another level was included that comes between representational or possible fantasy (e.g., doctors) and impossible fantasy (e.g., witches): improbable fantasy (e.g., astronauts). Improbable fantasy incorporates entities and events that are theoretically possible because they do not violate any physical laws, but are practically or socially unlikely 
for the majority of people living in a particular context. Examples of improbable events might include owning a pet lion, meeting the Queen, or living in a tree house. Shtulman and Carey (2007) defined these events as ones that violate contingent truths, such as that lions live in the wild, or those that are statistically rare everyday occurrences, such as meeting the Queen or living in a tree house. These can be considered as upholding scientific principles, but are somewhat fantastical in their violation of what is normal in reality.

There are conceptual differences in the metaphysical possibilities that arise when engaging in representational/possible fantasy (e.g., pretending to be doctors), improbable fantasy (e.g., pretending to be astronauts), and impossible fantasy (e.g., pretending to be witches). Engaging in impossible fantasy (and to some extent, improbable fantasy) provides an infinite number of ways of achieving one's goals because normal restrictions imposed by metaphysical scientific principles do not apply. In contrast, representational or possible acts of fantasy play tend to conform to these principles (Harris, Kavanaugh, Wellman, \& Hickling, 1993). Children with a high FO, or those who engage in more improbable or impossible fantasy, thus construct a world that is more counter-to-reality than children with a low FO (Runco \& Pina, 2013). This possibility is supported by results from Subbotsky, Hysted and Jones (2010) who found that children who watched a fantastical episode (from the film series featuring a wizard named Harry Potter) scored higher on creativity tasks than those who watched a non-fantastical, but equally engaging episode from the same film.

In the current study, children's scores were examined in three different ways for the purposes of analysis. First, a binary system was used, categorising children as producing either reality oriented or fantasy-oriented responses to determine whether there was an effect of these two categories on creativity (Taylor \& Carlson, 1997). Second, the four-point FO coding system was used to explore mode of FO on creativity, to determine whether, for 
example, impossible fantasy was associated with more creative responses than improbable fantasy. Finally, an average FO score was used to explore linear relations with FO and creativity. Following Silverman's (2016) conclusions, the hypothesis was that there would be significant relations between FO and creativity.

The strength of the relation between FO and creativity may, however, be dependent on other factors, including what domain of creativity is assessed in a creative thinking task, as well as individual differences, such as age or gender. Taylor et al. (2020) found evidence suggesting a link between FO and creativity for some of their creativity tasks in 8- to 12-yearolds but not for others. They found that children who invented imaginary worlds, or paracosms, provided a more creative ending to a story stem than children who had not invented paracosms. They also drew a more creative pretend person (see also Mottweiler \& Taylor, 2014). However, there was no difference between the two groups of children on a divergent thinking task (generating alternate uses for an empty milk carton), a make a 'silly' collage task, or on a social consequences task in which children had to explain how the world would be different if people had tails. That said, there were positive correlations between scores on three creativity tasks that involved a more social element - story stem, draw a pretend person, and social consequences. Although Taylor et al. (2020) generally did not find any gender differences, girls produced more creative story endings than boys, and age was correlated with the alternate uses divergent thinking task. These findings thus lend support to the view that creativity is domain specific rather than domain general, and that FO may be differentially related to different domains of creativity (Baer, 2012; Kaufman, 2012).

However, results from another study do not strongly support these conclusions. Subbotsky et al. (2010) examined the relations between exposure to fantasy for different 
domains of creative performance in 4-6-year-olds. As mentioned earlier, one group of children watched a fantastical episode from the film series featuring a wizard named Harry Potter, and another group watched an equally engaging but non-fantastical clip from the same series. Children then completed a movement creativity task involving different ways to put a plastic cup into a bin, as well as a verbal task involving generating alternate uses for a cup, and a drawing task in which they had to draw a non-existent object (e.g. an animal and a house). Subbotsky et al. (2010) found that children in the fantastical film group were more creative on all of these measures compared to children in the non-fantastical film group, lending support to the view that creativity may be domain general. While they did not examine gender differences, the 6 year-olds achieved higher creativity scores than the 4 year-olds.

Although Subbotsky et al. (2010) did not directly assess individual differences in FO, and Taylor et al. (2020) found differences between FO and some creativity tasks in older children, it seems important to explore further the potential relations between FO and different domains of creativity in early childhood, and potential differences in age and gender. In the current study, we included three tests of creativity that loosely correspond to Kaufman's (2012) three creativity domains: scholarly, performance, and artistic. Specifically, we included a verbal divergent thinking test, a physical movement task, and a draw a pretend person task. Given the theoretical arguments for a relation between FO and creativity we might expect relations between FO and all three creativity tests. However, given the evidence presented earlier that these relations might vary by type of creative output, we alternatively might expect to see domain differences. Regarding age and gender, given that some research has identified effects of these individual variables on FO and 
RUNNING HEAD: FANTASY ORIENTATION AND CREATIVITY

creativity (e.g., Taylor et al. 2020; Carlson \& Taylor, 2005; Subbotsky et al. 2010), we explored whether these interacted with the potential relation between FO and creativity.

\section{Method}

\section{Participants}

Seventy-two children aged between $4 ; 5$ and 7;11 ( $M=70$ months, $S D=13.19)$ participated. This sample size and age range was based on analysis of sample sizes used in comparable studies of children's FO and creativity, and captures children at an age when they are likely to engage in fantasy or have an imaginary companion (Singer \& Singer, 1990; Smith \& Lillard, 2012; Taylor, 1999). There were 39 (54\%) girls and 33 boys. For some analyses, children were divided into a younger age group $(4 ; 5-5 ; 11, M=60$ months, $S D=$ 6.09) and an older age group $(6 ; 0-7 ; 11, M=70$ months, $S D=7.04)$. Children were recruited through local schools and nurseries, and were all native English speakers with no known developmental disorders. Most children were White British.

\section{Materials}

The creativity tasks assessed three types of creative output: verbal, physical, and artistic. The verbal measure was the instances task (Wallach \& Kogan, 1965). In this task, children were asked to: "name all the things you can think of that are red". The physical measure of creativity was the 'How many ways?' subset of the TCAM (Torrance, 1981). Children were asked to move in as many ways as possible between two lines marked out on the floor with tape, approximately 3 meters apart. The example 'walking' was modelled. Finally the artistic creativity task required children to draw a picture of a real person, then draw a picture of: "a pretend person, a person that couldn't exist, a person that is made up" (adapted by Mottweiler \& Taylor, 2014, from Karmiloff-Smith, 1990). 
To assess FO, three measures were used that have been shown to be reliable and valid (Sharon \& Woolley, 2004): Singer and Singer's (1990) Imaginative Play Predisposition interview, Taylor and Carlson's (1997) Imaginary Companion interview (adapted from Taylor, Cartwright \& Carlson, 1993), and Taylor and Carlson's (1997) Impersonation interview. Children were asked the following 9 questions: 1) When you have time to play and you can choose anything you want, what do you love playing the most? 2) Do you have a favorite toy? 3) Do you have a favorite book that you like to look at? 4) Do you have a favorite TV show or something you like to watch? 5) Do you ever pretend to be an animal? 6) Do you ever pretend to be another person? 7) Do you ever pretend to be anything else like a machine, airplane or something like that? 8) Do you like dressing-up? 9) Do you have a pretend friend? If children answered yes to questions 1-8, they were asked a set of prompts that took the form of reiterating the question and asking for further information, for example, 'What's your favourite toy? Tell me all about it.' They were further prompted to elaborate on their answers as appropriate to obtain sufficient information to categorise their response as reality-oriented, possible fantasy, improbable fantasy, or impossible fantasy. Question 9 was introduced and followed up using the wording from Taylor, Cartwright and Carlson (1993).

\section{Procedure}

Parental consent was obtained for each child who took part. Two researchers visited schools and tested children individually in a suitable location outside of the classroom (e.g., the school library or sports hall). The three creativity tasks were conducted first, in a random order, followed by the FO assessment. This was conducted last so as to avoid any researcher bias during the creativity tasks as a result of knowing a child's FO. Once children had given at least one response on the instances test or movement test, they were prompted up to two 
further times unless they said that they could not think of any more things or ways. If it was not clear what children were doing in the movement task, they were encouraged to describe it to the researcher. For the drawing task, children were provided with a piece of A4 sized paper, presented horizontally, with a vertical black line dividing it equally in two. They were given a pack of 8 coloured pencils and shown where to draw each picture. When they had finished, they were asked to describe what they had drawn to the researcher. If necessary, the researcher made notes on the back of the drawings to clarify what the child had drawn.

The instances test and FO interview were audio recorded. All tasks were administered by one researcher, although the movement task was observed by two researchers. Because it was not possible to video record children in schools, each researcher wrote down a description of each way of moving in the movement task. Both researchers came to an agreement about the movements for each child after the task. The entire procedure lasted approximately 15-20 minutes.

\section{Coding and data analysis}

The instances and movement tests were coded using the same procedure. This involved calculating scores for fluency (number of ideas), and originality (novelty or statistical rarity). The latter was calculated using the method proposed by Runco, Okuda and Thurston (1987). In both tasks, the correlations between these two scores were highly significant and ranged between $r=.85$ and $r=.99$, therefore, for simplicity, the fluency score was used.

The drawing task was scored using Amabile's (1982) consensual assessment technique. Two coders, who did not have any information about performance across the other creativity tasks or the FO interview, were instructed to look at all the drawings and descriptions, then go through them a second time and rate each pretend person on a scale 
of $1-3$, where 1 = not very creative, 2 = somewhat creative and $3=$ very creative (see Figure 1 for example drawings). Originally we attempted to use a five point rating scale but this resulted in poor reliability, particularly between cagetories 4 and 5 , and 1 and 2 . The raters were encouraged to judge the drawings independently of drawing ability, that is, the creativity of the pretend person was rated for each child separately in comparision to the real person (not in comparison to other children's drawings). Agreement between the two coders was 90\% (kappa $=.79$ ). Disagreements were resolved between the two coders by a third coder.
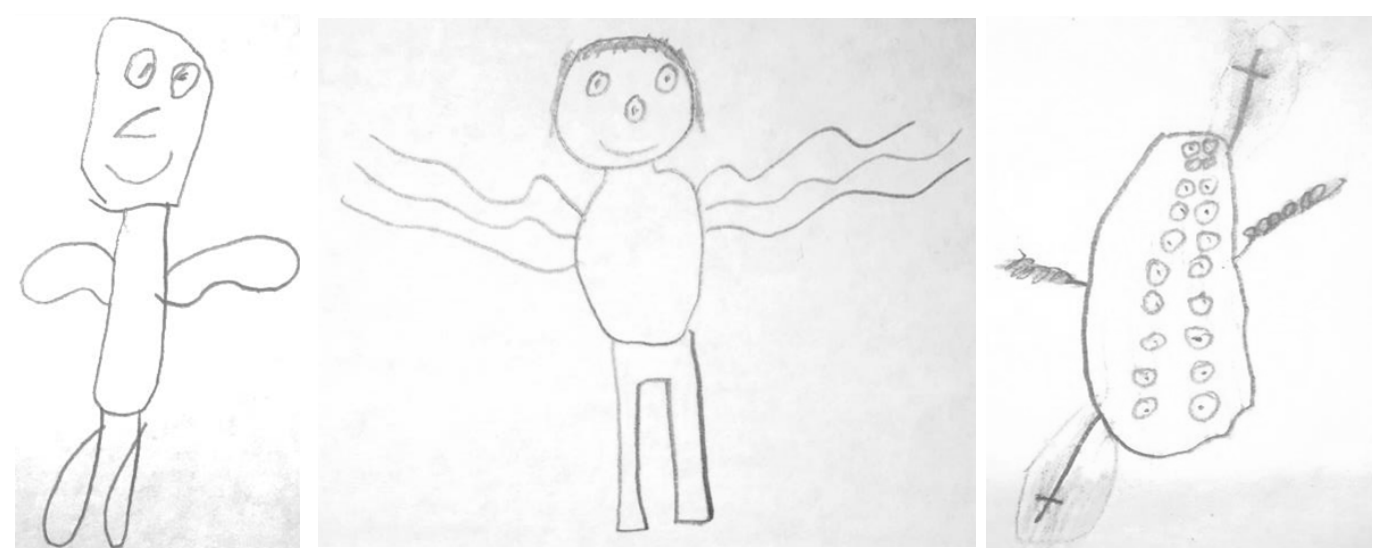

Figure 1: Examples of pretend people rated as uncreative (left), somewhat creative (middle), and highly creative (right).

The coding scheme for the FO interview was designed to distinguish between four levels of response that varied in their orientation toward reality: (1) reality-oriented (scored as 0); (2) possible fantasy (scored as 1); (3) improbable fantasy (scored as 2); and (4) impossible fantasy (scored as 3). The category reality-oriented was for play that did not primarily involve fantasy, such as playing football, making a bracelet, or playing a musical instrument. The category possible fantasy was for pretending, reading, or watching TV 
shows that involved real-life or possible entites or events, for example, pretending to be a teacher, playing with realistic Lego worlds such as a farm, or reading a story book about a trip to the park. The category improbable fantasy was for pretending, reading, or watching TV shows involving improbable entites or events, that is, those that are statistically rare or unlikely in Western children's everyday life but are nonetheless possible. These included, for example, pretending to be a pirate or reading a book about going to outer space. The final category was impossible fantasy. This category was for pretending, reading, or watching TV shows involving entites or events that are not possible, for example, pretending to be a fairy, reading a story about witches, or watching a film about the wizard Harry Potter. See Table 1 for sample responses to each question for each category of FO.

Coding decisions focused on the nature of the actions and events performed by the entities, rather than on the type of entity. For example, actions performed by Bob the Builder are reality-oriented, even though he is an imaginary character, so pretending to be Bob the Builder was coded as possible fantasy. Likewise, a character such as Pepper Pig, even though she is an animated, anthropomorphised character, performs common everyday actions such as going to school and cooking. These actions were coded so that if children said that Pepper Pig was their favourite toy, that response was coded as possible fantasy. In contrast, actions performed by Harry Potter, a wizard, are magical, so pretending to be Harry Potter or citing Harry Potter as their favourite book was coded as impossible fantasy. If the coders were unfamiliar with the name of a book, character or TV show, they researched it on the internet and based their coding decision on descriptions of the events and actions of the main characters. As was also found by Taylor and Carlson (1997), very few children pretended to be a machine, so this question was excluded from the analysis. Coding 
was carried out independently by two coders. Agreement between them was $82 \%$ (kappa $=$ .74). Disagreements were discussed and an agreement was reached.

Table 1: Examples of responses for each question according to level of fantasy orientation

\begin{tabular}{|c|c|c|c|c|}
\hline & & evel of fantasy orienta & tion and brief description & \\
\hline & $\underline{\text { Reality oriented }}$ & $\underline{\text { Possible Fantasy }}$ & Improbable Fantasy & Impossible Fantasy \\
\hline & $\begin{array}{l}\text { Does not involve } \\
\text { fantasy }\end{array}$ & Mirrors everyday life & $\begin{array}{l}\text { Child unlikely to } \\
\text { experience / }\end{array}$ & $\begin{array}{l}\text { Violates physical } \\
\text { laws / does not exist }\end{array}$ \\
\hline Question & & & encounter in daily life & \\
\hline Toy & Guitar & Lego & Soldiers & Batman \\
\hline & Colouring books & Sylvanian Families & My Little Pony & Ninja Turtles \\
\hline Book & Where's Wally? & Goodnight Already & Gangster Granny & The Chocolate Tree \\
\hline & A book about space & Guess how much I & Horrid Henry & Enchanted Woods \\
\hline & & love you & & \\
\hline TV show & Blue Peter & Thomas Tank Engine & Swashbucklers & Mia \& Me \\
\hline & Nina \& the Neurons & Pepper Pig & Octonauts & Ben Ten \\
\hline Animal & $\mathrm{N} / \mathrm{A}$ & Cat & Tiger & Unicorn \\
\hline & & Hamster & Wolf & \\
\hline Person & $\mathrm{N} / \mathrm{A}$ & Teacher & King & Mermaid \\
\hline & & Fireman & Princess & Zombie \\
\hline Dressing up & $\mathrm{N} / \mathrm{A}$ & Bob the Builder & Pirate & Harry Potter \\
\hline & & Fireman Sam & Knight & Elsa \\
\hline $\begin{array}{l}\text { Imaginary } \\
\text { companion }\end{array}$ & $\mathrm{N} / \mathrm{A}$ & $\begin{array}{l}\text { Joe, he has short } \\
\text { blonde hair, we play } \\
\text { football together }\end{array}$ & $\begin{array}{l}\text { Mia, an invisible really } \\
\text { tall girl with pink hair } \\
\text { and we hunt treasure }\end{array}$ & $\begin{array}{l}\text { An alien that comes } \\
\text { from the planet lgg } \\
\text { who is } 192 \text { years old }\end{array}$ \\
\hline
\end{tabular}

To explore the internal consistency of items comprising the FO interview, Guttman's Lambda-2 was calculated (Chronbach's alpha was not used because the covariances among the items were not equal). The score was $\alpha=.56$, which is low. When this is the case, particularly when the number of items is small, Tavakol and Dennick (2011) suggest 
correlating each item with the average score and deleting items with low correlations that appproach zero. This analysis revealed that each item correlated with the average score significantly, ranging from $r=.31$ to $r=.66$. Given this result, no items were deleted and all items were retained. Furthermore, we checked that inconsistent or dissimilar responses were not limited to a specific few items (Vaske, Beaman, \& Sponarski, 2017). This analysis indicated that the pattern of inconsistencies was random, providing further support for retaining all items.

\section{Results}

\section{Fantasy orientation: Descriptives}

Most (50,69\%) children answered all 8 FO questions. Seventeen (24\%) children answered 7 of the questions, a further three children (4\%) answered 6 questions, one child only answered 5 questions, and one child only answered 3 questions. The latter was excluded from further analysis, leaving a total sample size of 71 . The FO questions that were not answered were restricted to the first four questions regarding favourite book ( 9 children), TV show (7 children), toy ( 6 children), and free play (6 children). Missing data were excluded from the calculation of average scores, for example, if a child only answered 6 out of 8 questions they received an average score out of 6 . Children were categorised as belonging to one of the four categories of FO according to their modal response (see Table 2). Fifty-two of the 71 children (73\%) could be categorised in this way, meaning that they gave at least three responses that fell into the same category. Of the remaining children, 7 were bi-modal and 11 children were 'multi-modal', giving a variety of responses that included all four categories. 
Table 2: Number of children with each mode of fantasy orientation according to age group and gender

\begin{tabular}{|c|c|c|c|c|}
\hline & \multirow[t]{2}{*}{ Gender } & \multicolumn{2}{|c|}{ Age Group } & \multirow[t]{2}{*}{ Total } \\
\hline & & Younger & Older & \\
\hline \multirow[t]{3}{*}{ Reality oriented } & Girl & 1 & 2 & 3 \\
\hline & Boy & 7 & 1 & 8 \\
\hline & Subtotal & 8 & 3 & 11 \\
\hline \multirow[t]{3}{*}{ Possible Fantasy } & Girl & 4 & 9 & 13 \\
\hline & Boy & 6 & 3 & 9 \\
\hline & Subtotal & 10 & 12 & 22 \\
\hline Improbable & Girl & 3 & 2 & 5 \\
\hline \multirow[t]{2}{*}{ Fantasy } & Boy & 2 & 2 & 4 \\
\hline & Subtotal & 5 & 4 & 9 \\
\hline Impossible & Girl & 4 & 4 & 8 \\
\hline \multirow[t]{3}{*}{ Fantasy } & Boy & 1 & 1 & 2 \\
\hline & Subtotal & 5 & 5 & 10 \\
\hline & Total & 28 & 24 & 52 \\
\hline
\end{tabular}

\section{Relations between fantasy orientation and creativity when fantasy orientation is} operationalised as a binary

First we examined whether there would be an effect of FO on creativity scores using a binary (present/absent) categorisation system. Each response was categorised as either 'Reality Oriented', meaning not engaging in any form of representational play, or 'Fantasy Oriented', meaning that some form of fantasy was produced (possible, improbable, or 
impossible). Children were then classified according to their modal response. A multivatiate ANOVA was conducted with FO mode ( 0 = reality oriented, $1=$ fantasy oriented, combining possible , improbable, and impossible), age group (4-5 year-olds, 6-7 year-olds), and gender (girls, boys) as the IVs, and the physical, verbal, and artistic creativity tasks as the DVs.

Age was significantly related to physical creativity $(p=.026)$, and approached significance for verbal creativity $(p=.089)$, but was not related to artistic creativity $(p=$ .181). There were no effects of gender on creativity and no interactions. The effect of FO mode on creativity was not significant for verbal creativity, $F(1,51)=.969, p=.330, \eta^{2}=.022$, or artistic creativity, $F(1,51)=.292, p=.592, \eta^{2}=.007$, although, it was significant for physical creativity, $F(1,51)=8.760, p=.005, \eta^{2}=.166$. Pairwise comparisons revealed that children whose mode was Fantasy Oriented produced significantly more ways of moving ( $M$ $=.75, S E=.036)$ than children whose mode was Reality Oriented $(M=.46, S E=.089)$. These data thus provided limited support for using a binary method of operationalising FO when exploring its relations to creativity.

\section{Relations between fantasy orientation and creativity when fantasy orientation is}

\section{operationalised according to level of impossibility}

To examine whether FO has stronger relations to creativity when level of impossibility is considered, we first explored whether there were any associations between the four FO modes (reality-oriented, possible, improbable, impossible) with age (4-5 yearolds, 6-7 year-olds) and gender (girls, boys) (see Table 2). Owing to small numbers of children in some of the categories, however, this analysis should be considered exploratory. A chi squared test on the relation between FO mode and age group indicated that there was no association, $\chi^{2}(3, n=52)=2.344, p=.504$. Similarly, there was no significant association between FO mode and gender, $\chi^{2}(3, n=52)=6.362, p=.095$, although girls were somewhat 
more likely to engage in impossible fantasy (21\%) than boys (6\%), and boys were somewhat more likely to engage in reality-oriented activities (25\%) than girls (8\%).

To explore the hypotheses regarding FO mode and creativity, we examined whether there were associations between the FO modes and each creativity task. A multivatiate ANOVA was conducted with mode $(0=$ reality oriented, $1=$ possible fantasy, $2=$ improbable fantasy, 3 = impossible fantasy, 4 = other mode), age group (4-5 year-olds, 6-7 year-olds), and gender (girls, boys) as the IVs, and the three creativity tasks as the DVs.

Age was significantly related to both verbal $(p=.04)$ and physical $(p=.007)$ creativity, and approached significance for artistic creativity $(p=.06)$. There were no effects of gender on creativity and no interactions. The effect of FO mode was not significant for verbal creativity, $F(4,70)=1.328, p=.272, \eta^{2}=.094$, or artistic creativity, $F(4,70)=.505, p=.732$, $\eta^{2}=.038$, although, it approached significance for physical creativity, $F(4,70)=2.192, p<.08$, $\eta^{2}=.147$. Pairwise comparisons revealed children whose mode was possible fantasy produced significantly more ways of moving $(M=.78, S E=.054)$ than children whose mode was reality oriented $(M=.46, S E=.095), p<.05$.

This analysis suggests that considering FO in a more detailed categorical way than the binary method also does not provide strong evidence for relations between FO and creativity. It also does not show that any one particular type of FO is related to verbal or artistic creativity more than another type. However, we uncovered suggestive evidence that engaging in possible fantasy, such as pretending to have a tea party, may be more strongly related to physical creativity than reality oriented play, such as playing sport. 


\section{Relations between fantasy orientation and creativity when fantasy orientation is}

\section{operationalised on a continuum}

The final test of the relation between FO and creativity was conducted by treating FO scores on a continuum, with low scores $(0)$ representing a reality orientation and high scores (3) representing an impossible fantasy orientation. The average FO score was 1.29 (SD =.48, range $=0.25-2.25)$. Initially, the effects of age group (4-5 year-olds and 6-7 year-olds) and gender (girls and boys) (the IVs) on FO score (the DV) were examined by conducting a univariate ANOVA. (see Figure 2). There was no main effect of age, $F(1,71)=.654, p=.422$, $\eta^{2}=.01$, but there was a significant main effect of gender, $F(1,71)=5.045, p<.028, \eta^{2}=.069$ : girls had a higher FO score $(M=1.41, S E=.07)$ than boys $(M=1.16, S E=.08)$. There was no age $x$ gender interaction, $F(1,71)=2.830, p=.097, \eta^{2}=.04$.

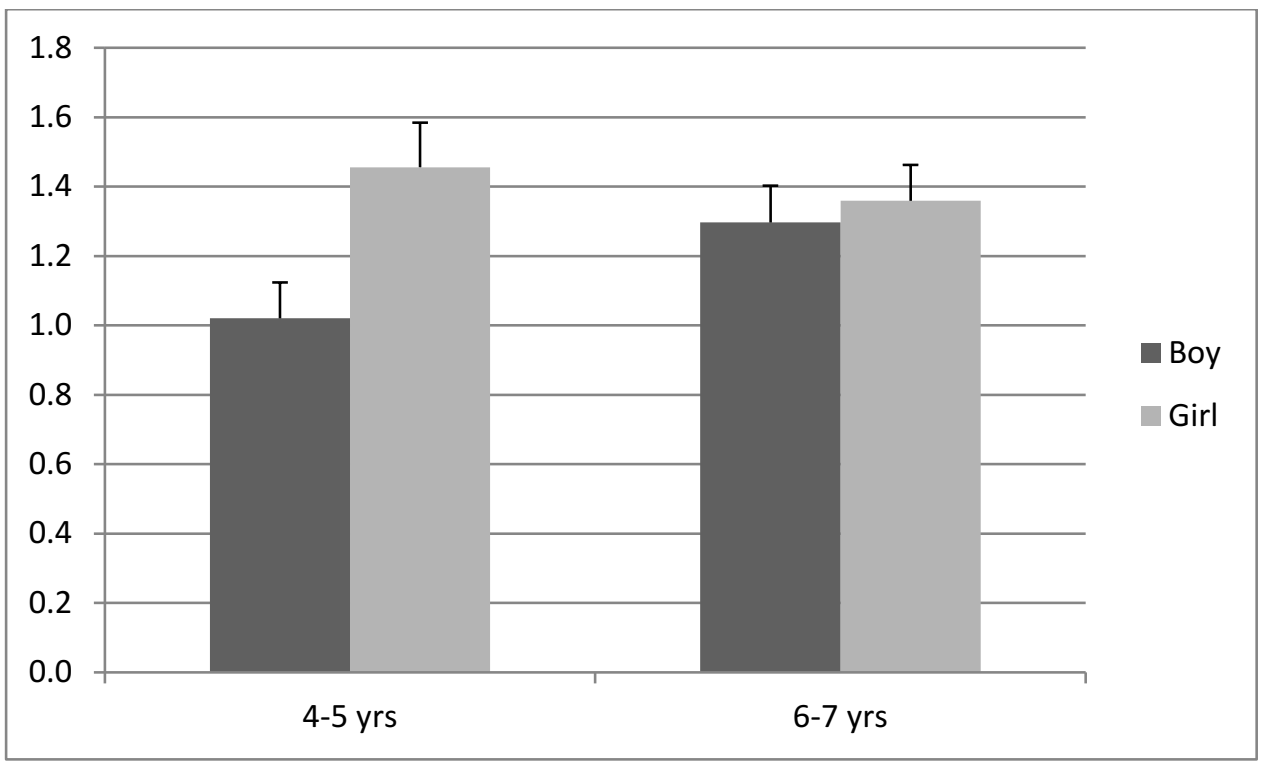

Figure 2: Average fantasy orientation score according to age and gender

We tested the hypothesis that there would be significant positive relations between average FO scores and creativity scores, with children who scored higher in FO being more 
creative. Table 3 provides the raw correlations among the key variables. Three separate linear regressions were conducted for each creativity task to test these hypotheses (see Table 4).

Table 3: Correlations among the key variables

\begin{tabular}{llllll}
\hline & & 1 & 2 & 3 & 4 \\
\hline 1 & Age & & & \\
2 & Fantasy orientation & 0.079 & & & \\
3 & Verbal creativity & $.280^{*}$ & $.244^{*}$ & & \\
4 & Physical creativity & $.417^{* *}$ & $.345^{* *}$ & $.309 * *$ & \\
5 & Artistic creativity & $.298^{*}$ & 0.165 & .065 & $.346 * *$ \\
$* p<.05, * * p<.01$ & & & &
\end{tabular}

\section{Verbal creativity - instances task}

A linear regression was conducted to examine whether performance on the instances task (the dependent / outcome variable) was related to FO, age, and gender (the independent / predictor variables). The regression equation was significant, $F(3,70)=3.850$, $p=.013$, with $\mathrm{R}=.38$, and Adjusted $\mathrm{R}^{2}=.11$, indicating that the model explained a significant amount of variance in verbal creativity scores. FO positively predicted performance on the instances task, indicating that children with higher FO produced more instances of things that were red. Age was also a significant positive predictor of creativity, whereby children produced more instances of things that were red with increasing age. Gender was not significant. These data thus support the hypothesis that higher levels of FO are associated with more creative performance. 


\section{Physical creativity - movement task}

A second linear regression was performed to determine whether FO, age, and gender were related to performance on the movement task. The regression equation was significant, $F(3,70)=9.111, p<.001$, with $R=.54$, and Adjusted $R^{2}=.26$, indicating that the model explained a significant amount of variance in movement scores. FO positively predicted a significant amount of variance in movement scores, indicating that children with higher FO demonstrated more ways of moving between the lines. Age was also a significant positive predictor of creativity, indicating that more ways of moving were produced with increasing age. Gender was not significant. These data also support the hypothesis that FO would be positively correlated with creative performance.

\section{Artistic creativity - drawing task}

Finally, a linear regression was performed to determine whether FO, age, and gender predicted performance on the drawing task. The regression equation was significant, $F(3$, 70) $=2.867, p=.043$, with $R=.34$, and Adjusted $R^{2}=.08$, indicating that the model explained a significant amount of variance in drawing scores. FO was not, however, a significant predictor of creative drawing, and neither was gender. In contrast, age was a significant predictor, indicating that children produced more creative drawings with increasing age.

\section{Discussion}

Fantasy orientation (FO) has emerged in recent years as a critical individual difference variable for understanding important aspects of children's cognitive development. Recent studies have found that children's FO is predictive of two foundational cognitive abilitiesExecutive Function (Pierucci, et al. 2014; Thibodeau et al. 2016) and Theory of Mind (Taylor \& Carlson, 1997; Dore \& Lillard, 2015). Evidence concerning the relation between FO and a third ability, creativity, is mixed, but given the conceptual similarities between FO and 
Table 4: Predictors of creativity, with $95 \%$ bias corrected confidence intervals reported in parenthesis

\begin{tabular}{|c|c|c|c|c|c|c|}
\hline & B & SE B & $b$ & $t$ & $p$ & VIF \\
\hline \multicolumn{7}{|c|}{ Verbal creativity } \\
\hline \multirow[t]{2}{*}{ FO } & .180 & .078 & .271 & 2.306 & $=.024$ & 1.085 \\
\hline & $(.024, .336)$ & & & & & \\
\hline \multirow[t]{2}{*}{ Age } & .007 & .003 & .270 & 2.372 & $=.021$ & 1.017 \\
\hline & $(.001, .012)$ & & & & & \\
\hline \multirow[t]{2}{*}{ Gender } & -.065 & .076 & -.102 & -0.864 & $=.390$ & 1.093 \\
\hline & $(-.216, .086)$ & & & & & \\
\hline \multicolumn{7}{|c|}{ Physical creativity } \\
\hline \multirow[t]{2}{*}{ FO } & .190 & .058 & .352 & 3.284 & $=.002$ & 1.085 \\
\hline & $(.075, .306)$ & & & & & \\
\hline \multirow[t]{2}{*}{ Age } & .008 & .002 & .404 & 3.889 & $<.001$ & 1.017 \\
\hline & $(.004, .012)$ & & & & & \\
\hline \multirow[t]{2}{*}{ Gender } & -.071 & .056 & -.136 & -1.262 & $=.221$ & 1.093 \\
\hline & $(-.183, .041)$ & & & & & \\
\hline \multicolumn{7}{|c|}{ Artistic creativity } \\
\hline \multirow[t]{2}{*}{ FO } & .188 & .213 & .016 & 0.883 & $=.380$ & 1.085 \\
\hline & $(-.237, .623)$ & & & & & \\
\hline \multirow[t]{2}{*}{ Age } & .018 & .007 & .285 & 2.456 & $=.017$ & 1.017 \\
\hline & $(.003, .033)$ & & & & & \\
\hline \multirow[t]{2}{*}{ Gender } & .137 & .206 & .080 & 0.664 & $=.509$ & 1.093 \\
\hline & $(-.274, .547)$ & & & & & \\
\hline
\end{tabular}

creativity, more research on these potential relations is a crucial next step in extending our understanding of the role of FO in children's cognitive development. In the current study, we introduced a new method for measuring children's FO by categorizing children's fantasyoriented activities along a continuum from realistic to impossible. We also included three 
creativity tasks to tap into different domains of creativity to explore further the potential relations between FO and creativity. Our findings provide new information both about the nature of children's FO and about the relations between FO and creativity.

In the current study, we demonstrated the feasibilty of rating children's FO on a fourpoint scale by including responses that were reality-oriented, involved possible fantasy, improbable fantasy, or impossible fantasy. This provided a more detailed portrait of the types of fantasy activities in which children engage compared with a binary characterization (reality oriented or fantasy oriented (including possible fantasy, improbable fantasy, and impossible fantasy). When the data were scored according to a binary system, FO was only associated with physical creativity. Specifically, children whose mode was fantasy oriented produced more ways of moving across the floor than children whose mode was reality oriented. However, when using the four-point scale for scoring children's responses, our hypotheses were largely supported by finding significant positive correlations between FO and creativity in two of the three domains assessed (verbal and physical). This comparison between the two scoring methods demonstrates the value of using a more nuanced coding system for FO to explore its relations with other cognitive abilities. The results using the four-point scale are also consistent with the findings of previous studies suggesting that there is a relation between engaging in fantasy and some types of creative performance (Mottweiler \& Taylor, 2014; Silverman, 2016; Taylor et al. 2020).

The finding that FO was not related to artistic creativity when FO was assessed using either the binary coding system or the four-point scale did not support our hypothesis. It was especially surprising given that Taylor et al. (2020) did find an effect of creating fantastical or imaginary worlds on the same draw a pretend person task, although that effect only emerged in one of their two studies. One factor that makes the drawing task 
different from other divergent thinking tasks is that it involves a 'people' or social element. Taylor et al. (2020) proposed that there may be important differences between social creativity tasks (such as story stem and draw a person) and nonsocial ones on the basis of research by Mottweiler and Taylor (2014) who found differences in social creativity in preschoolers with and without imaginary companions. However, if social content was important we would have expected to find a relation between FO and artistic creativity, which we did not. Another possibility is the difficulty in scoring children's drawings on a 5point scale. Owing to lack of rater reliability, scores were allocated on a 3-point scale, which reduced the scoring range and statistical power. Thus, it remains a possiblity that there is a relation between FO and artistic creativity, particularly if creativity is seen as a domain general skill that has conceptual links with FO.

We also found that it was possible to categorise the majority (73\%) of children according to their modal FO response to conduct exploratory analysis on the associations between the different FO modes and creativity tasks. There was no impact of FO mode on verbal or artistic creativity, however, children whose FO mode was possible fantasy produced more ways of moving across the floor than children whose mode was reality oriented. These analyses were preliminary owing to the small numbers of children within some of the modes, nonetheless, it may be useful for future studies to examine the relations between FO mode and different domains of creativity with larger sample sizes.

In considering why FO might be related to creativity, theoretical arguments support a more domain general view of creativity; it is not clear why FO would be more strongly related to creativity in some domains versus in others. Engaging in highly creative thought involves producing ideas that are counterfactual to reality, and transcend current reality in unique ways (Runco \& Pina, 2013). Engaging in fantasy by pretending to be fantastical 
characters, reading fantastical stories, or watching fantastical movies similarly involves exposure to ideas that go beyond reality. While reading a book about a unicorn, for example, children must imagine the impossible, which potentially involves more cognitive work than simply engaging with a book about cats or other real animals. A child who is simply making pretend tea can draw upon her memory of this and other realistic events, whereas a child who hears about a wizard creating a magic potion to turn someone into a frog has to use her cognitive skills to imagine this scenario. Engaging in fantasy and creative thinking thus both involve thinking 'outside-of-the-box' and producing novel ideas that are absent from reality. Because the tasks used in each domain vary methodologically, it is possible that tasks in some domains are more sensitive than others to differences in FO, or tap into fantastical tendencies more than others. A fruitful topic for further research might be to explore whether creativity is differentially related to social and non-social fantasy, ideally using more parallel tasks.

One limitation of the current study is that it did not address the causal direction of the relation between FO and creativity. It is equally possible that engaging in fantasy leads to improvements in creative performance or that being creative leads to more engagement in fantasy. However, other evidence suggests that engaging in fantasy may facilitate creative thinking rather than the other way around (see e.g., Walker \& Gopnik, 2013). Much of the experimental work reviewed by Silverman (2016) indicates that engaging in fantasy facilitates creative thinking processes rather than the reverse. In addition, Dore and Lillard (2015) found that FO predicted improvements in theory of mind longitudinally, suggesting that fantasy engagement helps children to develop an understanding of other people's minds. Finally, Thibodeau-Nielsen et al's. (2020) experimental study revealed that engaging in a daily 5-week fantastical pretense intervention, but not a realistic pretense intervention, 
resulted in improved executive function. These findings thus provide directional evidence that fantastical play may support the development of various cognitive functions.

It is also important to consider that an additional third variable may be responsible for the relation between FO and creativity, for example, parental level of creativity and/or encouraging engaging in fantasy. Research by Hoicka et al. (2016) found that there was a moderate to high correlation between measures of divergent thinking in infants and their parents. Although this link could be due to genetic or environmental factors, it is consistent with the idea that a third variable, such as parental support for creative exploration or endeavours, could help explain the relation between FO and creativity.

Other caveats concern our measures of creativity and task order. Bijvoet-van den Berg and Hoicka (2014) have argued that asking young children to answer the same question repeatedly, as in divergent thinking tasks, is not something that children are used to doing in everyday life. Similarly, Mottweiler and Taylor (2014, p. 278) have expressed concerns that divergent thinking tasks are unfamiliar and cognitively challenging for children, thus researchers should attempt to develop more child appropriate measures of creativity. In relation to task order, although we administered the creativity tasks first so that the researcher did not know anything about a child's FO, it is possible that children who gave more creative responses were prompted more during the FO interview to produce more fantastical responses. We mitigated against this risk with a set of standardised prompts, although this risk cannot be entirely eliminated without the use of a different researcher to administer the creativity tasks from the FO interview.

In conclusion, the current study found evidence of a link between FO and creativity in two domains: verbal and physical creativity. The present findings suggest that future research should consider children's FO as occurring on a continuum from reality-oriented to 
purely fantastical, rather than dichotomizing it, but this may depend on the nature of the task or domain of creativity under investigation. Given the importance of creative thinking for solving and coping with everyday problems across the lifespan (Mouchiroud \& Lubart, 2001), future work should also investigate the extent to which we can enhance our creative potential by engaging in fantasy.

Acknowledgments: the authors would like to thank Elizabeth Boerger, Sophie Lockley, and Sarah Palmer for their contributions to this research. 
RUNNING HEAD: FANTASY ORIENTATION AND CREATIVITY

\section{References}

Amabile, T. M. (1982). Social psychology of creativity: A consensual assessment technique. Journal of Personality and Social Psychology, 43(5), 997-1013.

Baer, J. (2012). Domain specificity and the limits of creativity theory. The Journal of Creative Behavior, 46, 16-29.

Bijvoet-van den Berg, S. \& Hoicka, E. (2014). Individual differences and age-related changes in divergent thinking in toddlers and preschoolers. Developmental Psychology, 50(6), 1629-39.

Boerger, E. A., Tullos, A., \& Woolley, J. D. (2009). Return of the Candy Witch: Individual differences in acceptance and stability of belief in a novel fantastical being. British Journal of Developmental Psychology, 27(4), 953-970.

Carlson, S. M. \& Taylor, M. (2005). Imaginary companions and impersonated characters: Sex differences in children's fantasy play. Merrill-Palmer Quarterly, 51(1), 93-118.

Carlson, S. M. \& Zelazo, P. D. (2008). Symbolic thought. In M. Haith \& J. Benson (Eds.), Encyclopedia of Infant and Early Childhood Development, Vol 3 (pp. 288-297). London: Elsevier.

Dansky, J. L., \& Silverman, I. W. (1973). Effects of play on associative fluency in preschoolaged children. Developmental Psychology, 9(1), 38-43.

Dore, R. A. \& Lillard, A. S. (2015). Theory of mind and children's engagement in fantasy worlds. Imagination, Cognition and Personality, 34(3), 230-242.

Harris, P. L. (2000). Understanding Children's Worlds. The Work of the Imagination. Malden: Blackwell Publishing.

Harris, P. L., Kavanaugh, R. D., Wellman, H. M., \& Hickling, A. K. (1993). Young children's 
understanding of pretense. Monographs of the society for research in child development, i-107.

Hoicka, E., Mowat, R., Kirkwood, J., Kerr, T., Carberry, M., \& Bijvoet-van den Berg, S. (2016). One-year-olds think creatively, just like their parents. Child Development, 87(4), 1099-1105.

Kaufman, J. C. (2012). Counting the muses: development of the Kaufman domains of creativity scale (K-DOCS). Psychology of Aesthetics, Creativity, and the Arts, 6(4), 298308.

Karmiloff-Smith, A. (1990). Constraints on representational change: Evidence from children's drawing. Cognition, 34(1), 57-83.

Lillard, A. (2001). Pretend play as twin earth: A social-cognitive analysis. Developmental Review, 21(4), 495-531.

Lillard, A. S., Lerner, M. D., Hopkins, E. J., Dore, R. A., Smith, E. D., \& Palmquist, C. M. (2013). The impact of pretend play on children's development: A review of the evidence. Psychological Bulletin, 139(1), 1-34.

Magid, R. W., Sheskin, M., \& Schulz, L. E. (2015). Imagination and the generation of new ideas. Cognitive Development, 34, 99-110.

Mouchiroud, C. \& Lubart, T. (2001). Children's original thinking: An empirical examination of alternative measures derived from divergent thinking tasks. The Journal of Genetic Psychology, 162(4), 382-401.

Mottweiler, C. M. \& Taylor, M. (2014). Elaborated role play and creativity in preschool age children. Psychology of Aesthetics, Creativity, and the Arts, 8(3), 277-286.

Pierucci, J. M., O’Brien, C. T., Mclnnis, M. A., Gilpin, A. T., \& Barber, A. B. (2014). Fantasy 
orientation constructs and related executive function development in preschool: Developmental benefits to executive functions by being a fantasy-oriented child. International Journal of Behavioral Development, 38(1), 62-69.

Richert, R. A. \& Smith, E. I. (2011). Preschoolers' quarantining of fantasy stories. Child Development, 82(4), 1106-1119.

Runco, M. A., Okuda, S. M., \& Thurston, B. J. (1987). The psychometric properties of four systems for scoring divergent thinking tests. Journal of Psychoeducational Assessment, 5(2), 149-156.

Runco, M. A. \& Pina, J. (2013). Imagination and personal creativity. In Taylor, M. (Ed.), The Oxford Handbook of the Development of Imagination (pp. 379-386). Oxford, UK: Oxford University Press.

Silverman, I. W. (2016). In defense of the play-creativity hypothesis. Creativity Research Journal, 28(2), 136-143.

Sharon, T.L., \& Woolley, J.D. (2004). Do monsters dream? Children's understanding of the fantasy-reality distinction. British Journal of Developmental Psychology, 22, 293-310.

Sigel, I. E. (1970). The distancing hypothesis: A causal hypothesis for the acquisition of representational thought. In M. R. Jones (Ed.), Miami Symposium on the Prediction of Behaviour, 1968: Effects of Early Experience (pp. 99-118). Coral Gables, FL: University of Miami Press,

Shtulman, A. \& Carey, S. (2007). Improbable or impossible? How children reason about the possibility of extraordinary events. Child Development, 78(3), 1015-1032.

Singer, J. L. (1973). The child's world of make-believe: Experimental studies of imaginative play. New York: Academic Press.

Singer, D.G., \& Singer, J.L. (1990). The House of Make-Believe: Children's Play and the 
RUNNING HEAD: FANTASY ORIENTATION AND CREATIVITY

Developing Imagination. Cambridge, MA: Harvard University Press.

Smith, E. D. \& Lillard, A. S. (2012). Play on: Retrospective reports of the persistence of pretend play Into middle childhood, Journal of Cognition and Development, 13(4), 524-549.

Subbotsky, E., Hysted, C., \& Jones, N. (2010). Watching films with magical content facilitates creativity in children. Perceptual and Motor Skills, 111(1), 261-277.

Tavakol, M. \& Dennick, R. (2011). Making sense of Cronbach's alpha. International Journal of Medical Education, 2, 53-55.

Taylor, M. (1999). Imaginary Companions and the Children who Create them. New York: Oxford University Press.

Taylor, M. \& Carlson, S. M. (1997). The relation between individual differences in fantasy and theory of mind. Child Development, 68(3), 436-455.

Taylor, M., Cartwright, B.S., \& Carlson, S.M. (1993). A developmental investigation of children's imaginary companions. Developmental Psychology, 29, 276-285.

Taylor, M., Mottweiler, C. M., Aguiar, N. R., Naylor, E. R., \& Levernier, J. G. (2020). Paracosms: The imaginary worlds of middle childhood. Child Development, (91), e164-e178

Thibodeau, R. B., Gilpin, A. T., Brown, M. M., \& Meyer, B. A. (2016). The effects of fantastical pretend-play on the development of executive functions: An intervention study. Journal of Experimental Child Psychology, 145, 120-138.

Thibodeau-Nielsen, R. B., Gilpin, A. T., Nancarrow, A. F., Pierucci, J. M., \& Brown, M. M. (2020). Fantastical pretense's effects on executive function in a diverse sample of preschoolers. Journal of Applied Developmental Psychology, 68, 101137.

Torrance, E. P. (1981). Thinking Creatively in Action and Movement. Brensenville, IL: 
Scholastic Testing Service.

Vaske, J. J., Beaman, J., \& Sponarski, C. C. (2017). Rethinking internal consistency in Cronbach's Alpha. Leisure Sciences, 39(2), 163-173.

Walker, C. M. \& Gopnik, A. (2013). Pretense and possibility-a theoretical proposal about the effects of pretend play on development: Comment on Lillard et al. (2013). Psychological Bulletin, 139(1), 40-44.

Wallach, M. A. \& Kogan, N. (1965). Modes of Thinking in Young Children. New York: Holt, Rinehart and Winston.

Weisberg, D. S. (2015). Pretend play. Wiley Interdisciplinary Reviews: Cognitive Science, 6(3), 249-261.

Woolley, J. D. (1997). Thinking about fantasy: Are children fundamentally different thinkers and believers from adults? Child Development, 68(6), 991-1011.

Woolley, J. D., Boerger, E. A., \& Markman, A. B. (2004). A visit from the Candy Witch: Factors influencing young children's belief in a novel fantastical being. Developmental Science, $7(4), 456-468$. 